\title{
Remote collection of microorganisms at two depths in a freshwater lake using an unmanned surface vehicle (USV)
}

\author{
Craig Powers ${ }^{1}$, Regina Hanlon ${ }^{2}$, David Schmale ${ }^{\text {Corresp. } 2}$ \\ ${ }^{1}$ Department of Civil and Environmental Engineering, Virginia Polytechnic Institute and State University (Virginia Tech), Blacksburg, Virginia, United \\ States \\ 2 Department of Plant Pathology, Physiology, and Weed Science, Virginia Polytechnic Institute and State University (Virginia Tech), Blacksburg, VA, United \\ States \\ Corresponding Author: David Schmale \\ Email address: dschmale@vt.edu
}

Microorganisms are ubiquitous in freshwater aquatic environments, but little is known about their abundance, diversity, and transport. We designed and deployed a remoteoperated water-sampling system onboard an unmanned surface vehicle (USV, a remotecontrolled boat) to collect and characterize microbes in a freshwater lake in Virginia, USA. The USV collected water samples simultaneously at 5 and $50 \mathrm{~cm}$ below the surface of the water at three separate locations over three days in October, 2016. These samples were plated on a non-selective medium (TSA) and on a medium selective for the genus Pseudomonas (KBC) to estimate concentrations of culturable bacteria in the lake. Mean concentrations ranged from 134 to $407 \mathrm{CFU} / \mathrm{mL}$ for microbes cultured on TSA, and from 2 to $8 \mathrm{CFU} / \mathrm{mL}$ for microbes cultured on $\mathrm{KBC}$. There was a significant difference in the concentration of microbes cultured on KBC across three sampling locations in the lake $(P=$ 0.027), suggesting an uneven distribution of Pseudomonas across the locations sampled. There was also a significant difference in concentrations of microbes cultured on TSA across the three sampling days $(P=0.038)$, demonstrating daily fluctuations in concentrations of culturable bacteria. There was no significant difference in concentrations of microbes cultured on TSA $(P=0.707)$ and KBC $(P=0.641)$ across the two depths sampled, suggesting microorganisms were well-mixed between 5 and $50 \mathrm{~cm}$ below the surface of the water. About 1 percent (7/720) of the colonies recovered across all four sampling missions were ice nucleation active (ice+) at temperatures warmer than $-10^{\circ} \mathrm{C}$. Our work extends traditional manned observations of aquatic environments to unmanned systems, and highlights the potential for USVs to understand the distribution and diversity of microbes within and above freshwater aquatic environments. 


\section{Remote collection of microorganisms at two depths in a}

\section{2 freshwater lake using an unmanned surface vehicle (USV)}

3

4 Craig W. Powers ${ }^{1}$, Regina Hanlon ${ }^{2}$, David G. Schmale III ${ }^{2 *}$

5

$6{ }^{1}$ Department of Civil and Environmental Engineering, Virginia Tech, Blacksburg, Virginia

7 24061, USA

8 2Department of Plant Pathology, Physiology, and Weed Science, Virginia Tech, Blacksburg,

9 Virginia 24061, USA

10

11 *Corresponding author; dschmale@vt.edu / Phone 540-231-6943 / Fax 540-231-7477

12 


\section{ABSTRACT}

14 Microorganisms are ubiquitous in freshwater aquatic environments, but little is known about

15 their abundance, diversity, and transport. We designed and deployed a remote-operated water-

16 sampling system onboard an unmanned surface vehicle (USV, a remote-controlled boat) to

17 collect and characterize microbes in a freshwater lake in Virginia, USA. The USV collected

18 water samples simultaneously at 5 and $50 \mathrm{~cm}$ below the surface of the water at three separate

19 locations over three days in October, 2016. These samples were plated on a non-selective

20 medium (TSA) and on a medium selective for the genus Pseudomonas (KBC) to estimate

21 concentrations of culturable bacteria in the lake. Mean concentrations ranged from 134 to 407

$22 \mathrm{CFU} / \mathrm{mL}$ for microbes cultured on TSA, and from 2 to $8 \mathrm{CFU} / \mathrm{mL}$ for microbes cultured on

$23 \mathrm{KBC}$. There was a significant difference in the concentration of microbes cultured on KBC

24 across three sampling locations in the lake $(P=0.027)$, suggesting an uneven distribution of

25 Pseudomonas across the locations sampled. There was also a significant difference in

26 concentrations of microbes cultured on TSA across the three sampling days $(P=0.038)$,

27 demonstrating daily fluctuations in concentrations of culturable bacteria. There was no

28 significant difference in concentrations of microbes cultured on TSA $(P=0.707)$ and KBC $(P=$

29 0.641) across the two depths sampled, suggesting microorganisms were well-mixed between 5

30 and $50 \mathrm{~cm}$ below the surface of the water. About 1 percent (7/720) of the colonies recovered

31 across all four sampling missions were ice nucleation active (ice + ) at temperatures warmer than -

$3210^{\circ} \mathrm{C}$. Our work extends traditional manned observations of aquatic environments to unmanned

33 systems, and highlights the potential for USVs to understand the distribution and diversity of

34 microbes within and above freshwater aquatic environments. 


\section{INTRODUCTION}

36 The ecology of freshwater ecosystems is linked to the temporal and spatial dynamics of aquatic

37 microorganisms (Beisner et al., 2006). Microorganisms play an important role in the food web as

38 drivers and indicators of ecosystem health (Newton et al., 2011; Shafi et al., 2015). Biological

39 ice nucleators such as Pseudomonas syringae have been collected throughout the water cycle,

40 and have been implicated as drivers of precipitation processes (Ichinose 2013; Morris et al.,

41 2008). New research is needed to understand and predict the abundance, distribution, and

42 diversity of microorganisms in freshwater lakes (Morris et al., 2008). Humayoun et al. (2003)

43 observed differences in microbial diversity at different depths in Mono Lake, California, USA.

44 Song et al. (2007) examined distributions of toxins from algal blooms along the water column in

45 Lake Taihu, Wuxi, China. Pietsch et al. (2017) reported high concentrations of $P$. syringae in

46 Claytor Lake, VA, USA from the surface down to almost $10 \mathrm{~m}$. These authors also showed that

47 concentrations of $P$. syringae varied dramatically from day to day and location to location

48 (Pietsch et al., 2017). Though these observations have provided important data on the

49 distribution of microorganisms in aquatic environments, they have been limited by manned

50 collections (i.e., at least one human was needed to collect the samples). In this study, we extend

51 these manned observations to unmanned systems, highlighting the potential for robots to collect

52 samples to study the distribution and diversity of microbes within and above freshwater aquatic

53 environments allowing for precise and repeatable measurements.

54 Recent advances in unmanned systems have created new possibilities for sampling

55 natural and managed ecosystems (Pennington et al., 2016). Though these unmanned systems are

56 seeing increased use in a variety of scientific applications, many challenges must be overcome.

57 First, long-range control and communication of unmanned systems require high data rates, often 
58 more than satellite-based communication can provide. Commercial Wi-Fi systems are one

59 potential solution to fill this need (Takahata et al., 2016). Such systems have been used for

60 surface communication in autonomous underwater vehicles with a range of $1 \mathrm{~km}$ (Stokey et al.,

61 2005), and in specialized point to point sustained networks at ranges of over $100 \mathrm{~km}$ (Flickenger

62 et al., 2008). Second, object avoidance is an extremely important aspect of unmanned operations

63 and becomes an absolute requirement when operating in existing complex manned boat traffic.

64 Adaptive evaluation schemes and algorithms have been recently developed and tested to allow

65 autonomous watercraft to meet international regulations for preventing collisions at sea (Kuwata

66 et al., 2014; Shah et al., 2016).

67 In this manuscript, we describe the development and deployment of a USV to sample

68 water remotely at multiple depths and locations in a freshwater lake. This integrated system was

69 used to test the hypothesis that concentrations of microorganisms in Claytor Lake, VA vary with

70 depth, geographic location, and date of sampling. The specific objectives of this work were to (1)

71 develop an automated water sampler to remotely collect samples of water with a USV in a

72 freshwater lake, (2) conduct a series of field experiments to remotely collect samples of water

73 with the USV at two depths at three different locations in the lake, and (3) culture

74 microorganisms from the water samples on a non-selective medium (TSA) and on a medium

75 selective for the genus Pseudomonas (KBC) to estimate concentrations of culturable bacteria in

76 the lake. Our work represents a unique approach to collect and characterize the distribution of

77 microorganisms in aquatic environments, and could be extended to the tracking the movement of

78 hazardous agents during algal blooms and in floodwaters generated by hurricanes and other

79 extreme weather events. . 


\section{MATERIALS AND METHODS}

\section{Study site and design}

83 Samples were collected over three consecutive days on 25, 26, and 27 October, 2016 in Claytor

84 Lake, VA, USA. This freshwater lake has an approximate surface area of 18.2 square kilometers.

85 Samples were collected in a cove located at N37 $2.34^{\prime} 4^{\prime \prime} \mathrm{W} 80^{\circ} 37.7^{\prime} 9^{\prime \prime}$. The cove was selected in

86 part due to its isolation; no manned boats (other than our pontoon boat used as our base station)

87 visited the cove before or during our sampling operations. Water samples were collected at two

88 depths (5 and $50 \mathrm{~cm}$ ) below the water surface for three locations, L1 (N37 $2.33^{\prime} 4^{\prime \prime}$

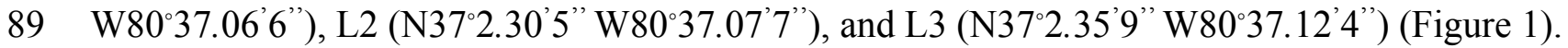

90 Depths of the lake at each of the sampling locations were measured with portable sonar sensor

91 (Signstek FF-003). The sensor was placed $20 \mathrm{~cm}$ below the surface of the water, and the depth

92 reader output screen was monitored until the continuous reading on the screen did not vary more

93 than $0.5 \mathrm{~m}$ for 10 readings. Depths for each of the locations were measured at $11 \mathrm{~m}$ for $\mathrm{L} 1,10 \mathrm{~m}$

94 for L2, and $4 \mathrm{~m}$ for L3. Sampling dates, times, and locations are provided in Table 1. Each

95 location was separated by the transition time of the USV between each location. GPS coordinates

96 were recorded for all navigation paths and each sample location (Figure 1). Though water

97 temperature is an environmental variable, it was assumed to be constant across the distances and

98 times within and among sample collections in this study.

100 Unmanned surface vehicle (USV)

101 A Clearpath Robotics Kingfisher USV (Clearpath Robotics, Kitchener, Ontario, Canada) (Figure

102 2) was used as our water-sampling platform. This electric USV weighed $28 \mathrm{~kg}$, was $1.35 \mathrm{~m} \mathrm{x}$

$1030.98 \mathrm{~m} \times 0.32 \mathrm{~m}(\mathrm{~L} \times \mathrm{W} \times \mathrm{H})$, had a maximum payload of $10 \mathrm{~kg}$, and was operated via remote 
104 control (the vehicle is equipped with autonomous navigation through a ground control station,

105 but this was not used during our mission because of limitations with obtaining consistent GPS

106 signals within the cove of interest). Each removable 29 Ah battery provided up to 3 hours of

107 continuous runtime. Differential thrust provided steering via the two impeller thrusters and

108 allowed for a maximum speed of $1.7 \mathrm{~m} / \mathrm{s}$. This platform enabled extremely precise, controlled

109 movements in shallow waters and also minimized water disturbances to the surrounding aquatic

110 environment that could be caused by the vehicle.

112 Development of an automated water sampler onboard a USV

113 A water sampler was developed for deployment on a USV with the goal of sampling at two

114 distinct depths for three locations (Figure 3). A vacuum system and flow rate was used to

115 maximize the water collection rate while minimizing turbulent fluid flow at the collection nozzle.

116 Seven $1 \mathrm{~L}$ bottles were used as the collection vessels. Two were used at each sampling location,

117 with each of the bottles holding a sample from each of the two depths $(5$ and $50 \mathrm{~cm})$. One bottle

118 was used as a control (no sample). Each bottle was attached via Tygon B-44-4X PVC 1/4" ID,

119 3/8" OD tubing to an air pump (ZT370-01, Dongguan Zhentian precision electronic co., LTD,

120 Dongguan city, Guangdong province, China.) calibrated to pull approximately $0.5 \mathrm{Lpm}$. Each

121 bottle had a section of this tubing attached to a stainless steel tube that served to siphon the water

122 directly from the lake. Six changeable siphons (one for each depth at each of three sampling

123 locations) were attached to arms on the water sampler platform via 3D printed bevel gears

124 (Supplemental File 1) that where actuated by waterproof servos (SX401WP, Hobbico Inc.,

125 Champaign, Illinois, USA). Two lengths of stainless steel tube were chosen to allow for

126 simultaneous collections at depths of 5 and $50 \mathrm{~cm}$ for each location. The tubing ends were bent 
127 into slight curves so that a water trap existed while the tubes were in the horizontal, stowed

128 position (Figure 2). Aliquots of $10 \mathrm{~mL}$ of sterilized water were placed into each of the six tubing

129 water traps to act as an environmental seal to prevent air flow movement and contamination of

130 the sampling tube while the USV proceeded through the sampling cycle. At the start of the

131 collection cycle at each location, one sampler arm transitioned from a rear horizontal stowed

132 position into the water, then past the vertical position and to a forward horizontal position, 175

133 degrees from the starting position, in order for the sterilized water to flow out of the tubing. This

134 cleared the line of sterile water preparing the system for water collection. The arm then

135 transitioned back into the water to a vertical position. Approximately $500 \mathrm{~mL}$ of water was then

136 siphoned simultaneously for both depths into a collection bottle for each depth. The arm then

137 transitioned back to the horizontal stowed position where water in the tubing (leftover from the

138 collection process) would stay in the water trap at the end of the tubing. This water served to

139 prevent contamination from the air while the USV completed the collection cycle. The stainless

140 steel tubing was disinfested with ethanol and flushed with sterile water after each sampling day,

141 and on the last day sterile water was used to flush the tubing between the two sampling periods

142 for that day. A microcontroller (keyestudio MEGA 2560, Chang Yong Rd., Longhua New

143 District, Shenzhen, China) in conjunction with servo and motor driver circuits, were integrated

144 into the water sampler and USV to control motion and timing of the servos and pumps. The

145 microcontroller was then controlled through the computer on the USV via a wireless link to a

146 portable computer running a Linux operating system.

147

148 Processing of Samples for Culturable Bacteria 
149 After the return of the USV from each collection cycle, the lake water samples were removed

150 from the USV and capped with sterilized screw cap lids. After all collections for the day were

151 completed, samples were transported on ice in a cooler to the lab for processing in the same $1 \mathrm{~L}$

152 collection bottle (Nalgene \#2187-0032). Subsamples of $250 \mathrm{~mL}$ from each collection bottle were

153 filtered through a $47 \mathrm{~mm}$ diameter, $0.22 \mathrm{~mm}$ GSWP nitrocellulose filter (Millipore\#9004-70-0)

154 in a sterile holder and receiver unit (Thomas \#300-4100). Filters were transferred to sterile 100

$155 \mathrm{~mL}$ bottles with $5 \mathrm{~mL}$ of the filtrate and a stir bar. Samples were stirred for $10 \mathrm{~min}$ to resuspend

156 microorganisms from the filter surface (resulting in a $50 \mathrm{X}$ concentration). A 0.5 dilution of this

157 resuspension (25X concentration) was used for plating. Kings B medium plus cycloheximide

158 (KBC), a medium semi-selective for Pseudomonas (Mohan et al., 1987), was used to plate 200

$159 \mu \mathrm{L}$ of both the $25 \mathrm{X}$ and $50 \mathrm{X}$ concentrations in triplicate. This medium consisted of $15 \mathrm{~g} / \mathrm{L}$

160 proteose peptone, $1.5 \mathrm{~g} / \mathrm{L}$ anhydrous K2HPO4, $10 \mathrm{~mL} / \mathrm{L} \mathrm{100 \%} \mathrm{glycerol,} 6 \mathrm{mM} \mathrm{MgSO} 4$ with 24

$161 \mathrm{mM} \mathrm{H3BO3,} \mathrm{cephalexin}(10 \mathrm{mg} / \mathrm{L})$, and cycloheximide $(50 \mathrm{mg} / \mathrm{L})$. Resuspended filtrates were

162 also plated onto $10 \%$ tryptic soy agar (TSA) plus cycloheximide $(50 \mathrm{mg} / \mathrm{L})$ at $25 \mathrm{X}, 5 \mathrm{X}$, and $0.5 \mathrm{X}$

163 concentrations to obtain counts of culturable bacteria on TSA (Hanlon et al., 2017). Colonies

164 were considered culturable if they showed visible growth on TSA after 4-6 days at $22^{\circ} \mathrm{C}$.

165 Following incubation, colony forming units (CFUs) were recorded from each plate (entire plates

166 were counted for KBC, and $1 / 2$ of each plate was counted for TSA), and the plates were held at

$1674^{\circ} \mathrm{C}$ for ice nucleation assays (Pietsch et al., 2017). The mean colony count for KBC plates at

$16825 \mathrm{X}$ concentration was $23 \mathrm{CFUs}$ per plate, providing more than the minimum 10 colonies needed

169 to screen 30 from each location from three plate replicates. This corresponded to $5 \mathrm{~mL}$ of lake

170 sample, and a mean of 4.6 CFU/mL. For TSA plates, the mean colony count at $5 \mathrm{X}$ concentration 
171 was 290 CFUs per plate. This corresponded to $1 \mathrm{~mL}$ of lake sample, and a mean of 290

$172 \mathrm{CFU} / \mathrm{mL}$.

173

174 Ice-nucleation assays

175 For ice nucleation assays, ten colonies were taken from three replicates of KBC plates, for a total 176 of 30 colonies from each sampling location. A total of 720 colonies was selected at random (180

177 from each of the four missions). Each colony was picked with a sterile toothpick and transferred

178 to $140 \mu \mathrm{L}$ of water. Two droplets of $12 \mu \mathrm{L}$ of each sample were pipetted onto floating boats

179 made of Parafilm ${ }^{\circledR}$ M placed on top of a cooling bath (Lauda Alpha RA 12, LAUDA-

180 Brinkmann, LP, Delran, NJ, 08075) (Hanlon et al., 2017). Droplets of sterile water were used as

181 negative controls. Samples were loaded onto the floating boats at $-5^{\circ} \mathrm{C}$, and the temperature of

182 the bath was then lowered to $-12^{\circ} \mathrm{C}$ in one degree increments. Freezing temperatures were

183 recorded for all of the frozen droplets. Microbes from droplets freezing at temperatures warmer

184 than $-10^{\circ} \mathrm{C}$ were considered to be ice nucleation active (designated as ice + ), and were identified

185 using portions of 16S rDNA sequences as described by Pietsch et al. (2017).

\section{Statistical analyses}

188 Statistical analyses were conducted using $\mathrm{R}$ version 3.4.0. A hierarchical model and linear

189 regression model were used to examine differences among culturable bacteria collected at 5 and

$19050 \mathrm{~cm}$ at three locations over three days. Four collection missions where conducted with one

191 mission per day on days one and two, and two missions on day three. Statistical comparisons

192 were made for missions one, two, and three (except when discussed otherwise). A Shapiro-Wilk

193 normality test was used to verify data were approximately normally distributed and graphically 
194 checked using density plots and histograms. A 95\% confidence interval was used for significant

195 differences $(P<0.05)$.

196

197 RESULTS

198 Missions

199 We conducted a total of twelve sampling missions (Table 1) with an automated water sampler

200 onboard a USV system. All missions were conducted from a pontoon boat (the mothership)

201 anchored in place along the shore of the cove at the center of the sampling operations. Three

202 sampling missions were completed in one continuous cycle each day for three days with an

203 additional cycle being added on the third and last day (Table 1). During each sampling mission,

204 the USV was controlled by remote control (RC), by the pilot in command (PIC, Schmale). The

205 sampler was operated by a wireless link from a ground control station by a sensor operator (SO,

206 Powers). Weather was clear with low to moderate winds and an average temperature of $11.7^{\circ} \mathrm{C}$

207 (Mission 1), 11.9 $\mathrm{C}$ (Mission 2), 12.2 ${ }^{\circ} \mathrm{C}$ (Mission 3), and 17.9 $\mathrm{C}$ (Mission 4) during time of 208 operation for each sampling day respectively.

210 Concentrations of bacteria on KBC and TSA

211 Concentrations $(\mathrm{CFU} / \mathrm{mL})$ of bacteria in water sampled from Claytor Lake were calculated using

212 colony counts from growth on KBC and TSA media (Table 1). Concentrations ranged from 126

$213 \mathrm{CFU} / \mathrm{mL}$ to $468 \mathrm{CFU} / \mathrm{mL}$ for microbes cultured on TSA, and from $2 \mathrm{CFU} / \mathrm{mL}$ to $46 \mathrm{CFU} / \mathrm{mL}$ for

214 microbes cultured on KBC (Table 1, Figure 4). There was a significant difference in

215 concentrations on $\mathrm{KBC}$ across three sampling locations in the lake $(P=0.027)$, suggesting an

216 uneven distribution of Pseudomonas across the locations sampled. There was also a significant 
217 difference in concentrations on TSA across the three sampling days $(P=0.038)$, demonstrating

218 daily fluctuations in concentrations of culturable bacteria. There was no significant difference in

219 concentrations on TSA $(P=0.707)$ and $\mathrm{KBC}(P=0.641)$ across the two depths sampled,

220 suggesting microorganisms were well-mixed between 5 and $50 \mathrm{~cm}$ below the surface of the

221 water.

222

223 Ice nucleation assays

224720 colonies (180 colonies from each of the four missions) were tested for ice nucleation activity

225 using a droplet freezing assay from $-5^{\circ} \mathrm{C}$ to $-12^{\circ} \mathrm{C}$. Of these, seven of the colonies were ice + at

226 temperatures $>-10^{\circ} \mathrm{C}$ (three ice + from mission 1, one ice+ from mission 2, two ice + from

227 mission 3, and one ice+ from mission 4). Of the seven that were ice+, two were identified as

228 Pseudomonas and one as Xanthomonas; genera that have been previously described as

229 containing species of biological ice nucleators (Hanlon et al. 2017).

230

231 


\section{DISCUSSION}

233 New technologies are needed to collect and characterize the distribution of microorganisms in

234 natural and managed aquatic environments. We developed and implemented a remote-operated

235 water sampler onboard an unmanned surface vehicle (USV) to collect samples at multiple depths

236 and locations. Traditional water sampling has used human-powered vehicles such as kayaks

237 (Pietsch et al., 2017) and motorized boats (Stang1, 2001), but these missions are limited by direct

238 human operation and line-of-sight operations. USVs have the potential to sample in remote

239 areas, operate beyond the line-of-site, and collect samples without any human intervention. Such

240 operations are needed in aquatic environments to increase our understanding of changes in

241 ecosystems and improve the accuracy of our long-term predictions.

242 The concentration of bacteria on both media types did not vary significantly between 5

243 and $50 \mathrm{~cm}$, when controlling for sampling location. Thus, the bacteria appeared to be well-mixed

244 between these two sampling depths. Pietsch et al. (2017) sampled water at the surface down to

245 about $10 \mathrm{~m}$, and observed no significant change in bacteria concentration with change in depth.

246 Future work with the USV could probe deeper depths in the lake, to get a more accurate picture

247 of the profile of microbes along the water column. It is possible that the difference in sampling

248 depth $(45 \mathrm{~cm})$ was too small to reveal any real changes in bacterial concentrations. The

249 maximum horizontal distance covered in this study was about $300 \mathrm{~m}$ in a small cove which could

250 also be a factor. Other environmental factors, such as seasonal temperature variation and $\mathrm{pH}$, are

251 additional factors that could have an impact on bacterial distributions (Lindströem et al., 2005).

252 Such seasonal and spatial changes are known to affect lake water chemistry, which in turn

253 impacts microbial composition in lakes (Parker et al., 2016). We speculate that samples collected 
254 at different depths could indeed show differences in concentrations of bacteria during specific

255 times of the year (i.e., during lake turnover) (Wilhelm et al., 2014).

256 There was a significant difference in concentrations on KBC across three sampling

257 locations in the lake $(P=0.027)$, suggesting an uneven distribution of Pseudomonas across the

258 locations sampled. KBC media is selective for bacteria in the genus Pseudomonas. Bacteria in

259 this genus are rod shaped, Gram-negative, and flagellated. The flagella enable Pseudomonas

260 syringae to have mobility. This mobility has been shown to be beneficial to the bacteria

261 (Lauffenburger, 1991), and is effected by temperature (Hockett et al., 2013). The difference in

262 concentrations across locations may be related to this mobility, at least in part. The lack of

263 significant change of concentration with location for the TSA media, could also be connected to

264 this mobility (or lack thereof) for many bacteria. TSA is a general media type that is not selective

265 for any particular bacteria, but is selective against fungal growth. Therefore, growth on this

266 media includes both motile and non-motile bacteria. The difference in concentrations for the two

267 locations (L1 and L2) may be related to geography; L1 was in a bend in the cove, offset slightly

268 from the flow of the feeding creek from the south, and L3 was near the mouth of the cove

269 opening up to the larger lake body (Figure 1). L1 may be an area of high sedimentation caused

270 by the redirection of water flow from the cove into the lake due to this bend. Claytor Lake is a

271 reservoir and has been reported to have a silt problem in the past (Simmons, 2004). The cove has

272 a narrow channelized basin impacting the trophic classification of the location towards eutrophic

273 (Kimmel and Groeger, 1984). Sediment, which can be high in organic content, is a point source

274 for bacteria including pathogenic strains (Kim et al., 2010). For example, concentrations of fecal

275 coliforms were orders of magnitude higher in sediments from an agricultural stream compared to

276 the overlying water column (Davies-Colley et al., 2004). The disturbance and re-suspension of 
277 this sediment can lead to large releases of microorganisms (Cinotto, 2005), and should be

278 considered in the design of future sampling campaigns.

279 There was no significant difference in the concentration of microbes across all days for

$280 \mathrm{KBC}$ media. However, there was a significant difference in the concentration of microbes from

281 day one to day three $(P=0.038)$ for TSA media when data from the second sampling mission on

282 day three (final day) are not included in the statistical analysis. Previous studies have reported

283 highly variable bacteria concentrations from day to day and location to location in the same day

284 for Claytor Lake (Pietsch et al., 2017). The undisturbed nature of the cove (limited human traffic

285 with power boats and decreased wind interaction with the water surface due to tree cover)

286 coupled with unique trophic characteristics, may contribute to the cove's decreased day to day

287 variation in concentrations of bacteria (Pietsch et al., 2017). Additional experiments including

288 additional coves, depths, and seasons are needed to monitor any additional trends in microbial

289 concentrations and potential feedback cycles.

290 About 1 percent (7/720) of the colonies from KBC media recovered across all four

291 sampling missions were ice nucleation active (ice + ) at temperatures warmer than $-10^{\circ} \mathrm{C}$. Similar

292 ratios of ice+ Pseudomonas and Xanthomonas were found in in simulated rain samples collected

293 from a bridge $55 \mathrm{~m}$ above ground level (Hanlon et al., 2017) and from real rain events at multiple

294 locations in Blacksburg, Virginia (Failor et al., 2017). Pietsch et al (2017) found $\sim 6.9 \%$ of ice +

295 strains in the main water body of Claytor Lake across multiple seasons. This greater percentage

296 of ice+ bacteria as compared to our study could be related to the open waters having exposure to

297 greater wind/surface interactions and could suggest that larger open bodies of freshwater are

298 preferential for some ice + bacteria. There is an important feedback cycle with microorganisms

299 and weather as they transport from aquatic environments into the atmosphere and back down to 
300 the ground (Morris et al., 2013). These microorganisms are not only passengers along for a ride

301 in the water cycle but may also serve as instigators for precipitation, a vital component of the

302 water cycle. Some of these microorganisms pose health and economic risk while some serve

303 important beneficial roles effecting the food web and climate such as Pseudomonas syringae

304 which is both a plant pathogen and an ice nucleator that contributes to precipitation events across

305 the globe (Morris et al., 2014). Understanding this complex interaction with aquatic

306 environments and their inhabitants creates a rich field of study well suited to unmanned systems.

308 Conclusions

309 A remote-operated water-sampling system was used onboard a USV to collect and characterize

310 microbes in a freshwater lake in Virginia, USA. There was an uneven distribution of

311 Pseudomonas across the locations sampled. There was no significant difference in concentrations

312 of microbes across the two depths sampled, suggesting microorganisms were well-mixed

313 between 5 and $50 \mathrm{~cm}$ below the surface of the water. About 1 percent (7/720) of the colonies

314 recovered across all four sampling missions were ice nucleation active (ice+) at temperatures

315 warmer than $-10^{\circ} \mathrm{C}$. Our work extends traditional manned observations of aquatic environments

316 to unmanned systems, and highlights the potential for USVs to understand the distribution and

317 diversity of microbes within and above freshwater aquatic environments.

318 Tracking microorganisms such as Pseudomonas syringae throughout the entire water

319 cycle could help to reveal a fundamental component of the water cycle and its role in both local

320 and global weather and other important environmental processes (Morris et al., 2008). Such a

321 study would require unmanned systems working together to sample in and above the water.

322 Research conducted by autonomous coordinated systems (Kolling et al., 2016; Vardy, 2016) 
323 could reveal a wealth of information on transport patterns of microorganisms and associated

324 environmental impacts. These studies could be comprised of surface, aerial and ground vehicles

325 working as a heterogeneous swarm (Szwaykowska et al., 2015) to sample and characterize the

326 environment with sophisticated meteorological sensors (e.g., windspeed, air and water

327 temperature, solar radiation, etc.) and biological sensors (e.g., impingers (Lin et al., 1999) and

328 optical particulate counters (Lee et al., 2006)). Such studies could also include laboratory

329 measurements of CFU (Pietsch et al., 2017), and flow cytometry measurements for to

330 characterize cell sizes and concentrations (Buzatu et al., 2014). Future work using these highly

331 adaptive autonomous systems over diurnal and longer seasonal cycles could capture an

332 unprecedented in depth and detailed picture of the role of these microorganisms in a range of

333 environmental systems.

\section{References}

341

342

343

344

345

346

347

348

349

350

351

352
Beisner, B. E., Peres-Neto, P. R., Lindströem, E. S., Barnett, A., \& Longhi, M. L. (2006). The role of environmental and spatial processes in structuring lake communities from bacteria to fish. Ecology, 87, 2985-2991.

Buzatu, D. A., Moskal, T. J., Williams, A. J., Cooper, W. M., Mattes, W. B., \& Wilkes, J. G. (2014). An integrated flow cytometry-based system for real-time, high sensitivity bacterial detection and identification. PloS One, 9, e94254.

Cinotto, P. J. (2005). Occurrence of fecal-indicator bacteria and protocols for identification of fecal-contamination sources in selected reaches of the West Branch Brandywine Creek, Chester County, Pennsylvania. US Department of the Interior, US Geological Survey.

Davies-Colley, R., Nagels, J., Donnison, A., \& Muirhead, R. (2004). Flood flushing of bugs in agricultural streams. Water and Atmosphere, 12, 18-20. 
353

354

355

356

357

358

359

360

361

362

363

364

365

366

367

368

369

370

371

372

373

374

375

376

377

378

379

380

381

382

383

384

385

386

387

388

389

390

391

392

393

394

395

396

Failor, K. C., Schmale 3rd, D. G., Vinatzer, B. A., \& Monteil, C. L. (2017). Ice nucleation active bacteria in precipitation are genetically diverse and nucleate ice by employing different mechanisms. The ISME Journal.

Flickenger, R., Okay, S., Pietrosemoli, E., Zennaro, M., \& Fonda, C. (2008). Very long distance wi-fi networks. Proceedings of the Second ACM SIGCOMM Workshop on Networked Systems for Developing Regions, (pp. 1-6).

Hanlon, R., Powers, C., Failor, K., Monteil, C. L., Vinatzer, B. A., \& Schmale, D. G. (2017). Microbial ice nucleators scavenged from the atmosphere during simulated rain events. Atmospheric Environment, 163, 182-189.

Hockett, K. L., Burch, A. Y., \& Lindow, S. E. (2013). Thermo-regulation of genes mediating motility and plant interactions in Pseudomonas syringae. PLoS One, 8, e59850.

Humayoun, S. B., Bano, N., \& Hollibaugh, J. T. (2003). Depth distribution of microbial diversity in Mono Lake, a meromictic soda lake in California. Applied and Environmental Microbiology, 69, 1030-1042.

Ichinose, Y., Taguchi, F., and Mukaihara, T. (2013). Pathogenicity and virulence factors of pseudomonas syringae. Journal of General Plant Pathology, 79(5), 285-296.

Kim, J.-W., Pachepsky, Y. A., Shelton, D. R., \& Coppock, C. (2010). Effect of streambed bacteria release on E. coli concentrations: Monitoring and modeling with the modified SWAT. Ecological Modelling, 221, 1592-1604.

Kimmel, B. L., \& Groeger, A. W. (1984). Factors controlling primary production in lakes and reservoirs: a perspective. Lake and Reservoir Management, 1, 277-281.

Kolling, A., Walker, P., Chakraborty, N., Sycara, K., \& Lewis, M. (2016). Human interaction with robot swarms: A survey. IEEE Transactions on Human-Machine Systems, 46, 9-26.

Kuwata, Y., Wolf, M. T., Zarzhitsky, D., \& Huntsberger, T. L. (2014). Safe maritime autonomous navigation with COLREGS, using velocity obstacles. IEEE Journal of Oceanic Engineering, 39, 110-119.

Lauffenburger, D. A. (1991). Quantitative studies of bacterial chemotaxis and microbial population dynamics. Microbial Ecology, 22, 175-185.

Lee, S.-A., Adhikari, A., Grinshpun, S. A., McKay, R., Shukla, R., \& Reponen, T. (2006). Personal exposure to airborne dust and microorganisms in agricultural environments. Journal of Occupational and Environmental Hygiene, 3, 118-130.

Lin, X., Reponen, T. A., Willeke, K., Grinshpun, S. A., Foarde, K. K., \& Ensor, D. S. (1999). Long-term sampling of airborne bacteria and fungi into a non-evaporating liquid. Atmospheric Environment, 33, 4291-4298.

Lindströem, E. S., Kamst-Van Agterveld, M. P., \& Zwart, G. (2005). Distribution of typical freshwater bacterial groups is associated with $\mathrm{pH}$, temperature, and lake water retention time. Applied and Environmental Microbiology, 71, 8201-8206.

Mohan, S. K., \& Schaad, N. W.. (1987). An improved agar plating assay for detecting Pseudomonas syringae pv. syringae and P. s. pv. phaseolicola in contaminated bean seed. Phytopathology, 77, 1390-1395.

Morris, C. E., Conen, F., Alex Huffman, J., Phillips, V., Pöschl, U., \& Sands, D. C. (2014). Bioprecipitation: a feedback cycle linking Earth history, ecosystem dynamics and land use through biological ice nucleators in the atmosphere. Global Change Biology, 20, 341351. 
397

398

399

400

401

402

403

404

405

406

407

408

409

410

411

412

413

414

415

416

417

418

419

420

421

422

423

424

425

426

427

428

429

430

431

432

433

434

435

436

437

438

439

440

441

442

Morris, C. E., Monteil, C. L., \& Berge, O. (2013). The life history of Pseudomonas syringae: linking agriculture to earth system processes. Annual Review of Phytopathology, 51, 85104.

Morris, C.E., Sands, D.C., Vinatzer, B.A., Glaux, C., Guilbaud, C., Buffiere, A., Yan, S., Dominguez, H. and Thompson, B.M. (2008). The life history of the plant pathogen Pseudomonas syringae is linked to the water cycle. The ISME Journal, 2, 321-334.

Newton, R. J., Jones, S. E., Eiler, A., McMahon, K. D., \& Bertilsson, S. (2011). A guide to the natural history of freshwater lake bacteria. Microbiology and Molecular Biology Reviews, $75,14-49$.

Parker, S.R., West, R.F., Boyd, E.S., Feyhl-Buska, J., Gammons, C.H., Johnston, T.B., Williams, G.P. and Poulson, S.R. (2016). Biogeochemical and microbial seasonal dynamics between water column and sediment processes in a productive mountain lake: Georgetown Lake, MT, USA. Journal of Geophysical Research: Biogeosciences, 121, 2064-2081.

Pennington, J. T., Blum, M., \& Chavez, F. P. (2016). Seawater sampling by an autonomous underwater vehicle:"Gulper" sample validation for nitrate, chlorophyll, phytoplankton, and primary production. Limnology and Oceanography: Methods, 14, 14-23.

Pietsch, R. B., Vinatzer, B. A., \& Schmale III, D. G. (2017). Diversity and abundance of ice nucleating strains of Pseudomonas syringae in a freshwater lake in Virginia, USA. Frontiers in Microbiology, 8.

Shafi, S., Kamili, A. N., Shah, M. A., \& Bandh, S. A. (2015). Isolation, identification and distribution of culturable bacteria in Manasbal Lake, Kashmir Himalaya. Proceedings of the National Academy of Sciences, India Section B: Biological Sciences, 1-6.

Shah, B.C., Švec, P., Bertaska, I.R., Sinisterra, A.J., Klinger, W., von Ellenrieder, K., Dhanak, M. and Gupta, S.K. (2016). Resolution-adaptive risk-aware trajectory planning for surface vehicles operating in congested civilian traffic. Autonomous Robots, 40, 11391163.

Simmons, D. J. (2004, 3). Corps outlines 6-year plan for Claytor Lake. The Roanoke Times [VA]. Song, L., Chen, W., Peng, L., Wan, N., Gan, N., \& Zhang, X. (2007). Distribution and bioaccumulation of microcystins in water columns: a systematic investigation into the environmental fate and the risks associated with microcystins in Meiliang Bay, Lake Taihu. Water Research, 41, 2853-2864.

Stangl, M. J. (2001). An electrofishing raft for sampling intermediate-size waters with restricted boat access. North American Journal of Fisheries Management, 21, 679-682.

Stokey, R.P., Roup, A., von Alt, C., Allen, B., Forrester, N., Austin, T., Goldsborough, R., Purcell, M., Jaffre, F., Packard, G. and Kukulya, A. (2005). Development of the REMUS 600 autonomous underwater vehicle. OCEANS, 2005. Proceedings of MTS/IEEE, 13011304.

Szwaykowska, K., Romero, L. M.-y.-T., \& Schwartz, I. B. (2015). Collective motions of heterogeneous swarms. IEEE Transactions on Automation Science and Engineering, 12, 810-818.

Takahata, K., Shimizu, E., Umeda, A., Oode, T., Tsuchiya, T., \& Tamura, Y. (2016). Development of remotely operated unmanned boat with long-range Wi-Fi. Artificial Life and Robotics, 21, 365-370.

Vardy, A. (2016). Aggregation in robot swarms using odometry. Artificial Life and Robotics, 21, 443-450. 
443 Wilhelm, S. W., LeCleir, G. R., Bullerjahn, G. S., McKay, R. M., Saxton, M. A., Twiss, M. R., 444 \& Bourbonniere, R. A. (2014). Seasonal changes in microbial community structure and 445

446

447 activity imply winter production is linked to summer hypoxia in a large lake. FEMS

448 Microbiology Ecology, 87, 475-485. 
Figure 1. Unmanned surface vehicle (USV) navigation routes (Mission 1, red, Mission 2, green,

452 Mission 3, cyan, and Mission 4, blue) and sample locations L1, L2, and L3 (orange flags) for the 453 four missions conducted from October 25 th to October 27 th. The USV collected $500 \mathrm{~mL}$ of 454 water from at two depths $(5 \mathrm{~cm}$ and $50 \mathrm{~cm})$ for each location. Map data: Google, Commonwealth 455 of Virginia, DigitalGlobe.

Figure 2. The Clearpath Robotics Kingfisher USV equipped with the automated water sampler on Claytor Lake, VA, USA. The water sampler onboard the USV collected samples of water at two different depths. Each sample was collected into sterile $1 \mathrm{~L}$ bottles. The operation of the vacuum pumps and sampling tubes were remote-controlled through a microcontroller and 461 supporting electronics housed in a waterproof box. A collection bottle containing $500 \mathrm{~mL}$ of

462 sterile water was used as an unexposed control during each mission. Image courtesy of D.

463 Schmale.

Figure 3. Engineering design of the automated water sampler onboard the USV. The sampler

(A) consisted of a microcontroller and electronics (1) powered by a lithium iron phosphate battery (2) that actuated servos (3) to control siphon positions (4) and pump water into $1 \mathrm{~L}$ containers (5) with vacuum pumps (6). During vehicle movement, the siphon arms (B) were in the stowed configuration (7). Upon reaching the sampling location, the appropriate arm rotated 470175 degrees (8) to allow the sterile water in the tube to flow out. The arm then rotated back 90 471 degrees (9) into the water for collection. After a set amount of collection time, the arm returned 472 to the stowed configuration (7) before proceeding to the next location. 
473

474 Table 1. Mean concentrations of bacteria $(\mathrm{CFU} / \mathrm{mL})$ for $\mathrm{KBC}$ and TSA media. Data are reported 475 for four sampling missions, over three days, at three locations at Claytor Lake, VA (L1, L2, and 476 L3). Remote collections were performed with a water sampler onboard an unmanned surface 477 vehicle (USV), and $\sim 500 \mathrm{~mL}$ of water was collected for each depth $(5$ and $50 \mathrm{~cm})$ and location. 478 479

480 Figure 4. Concentrations of bacteria $(\mathrm{CFU} / \mathrm{mL})$ for TSA (A) and KBC (B) media at two depths 481 of 5 and $50 \mathrm{~cm}$ at the three locations L1, L2, and L3. 


\section{Figure 1}

Image of sampling routes and locations.

Unmanned surface vehicle (USV) navigation routes (Mission 1, red, Mission 2, green, Mission 3, cyan, and Mission 4, blue) and sample locations L1, L2, and L3 (orange flags) for the four missions conducted from October 25th to October 27th. The USV collected $500 \mathrm{~mL}$ of water from at two depths $(5 \mathrm{~cm}$ and $50 \mathrm{~cm})$ for each location. Map data: Google, Commonwealth of Virginia, DigitalGlobe. 


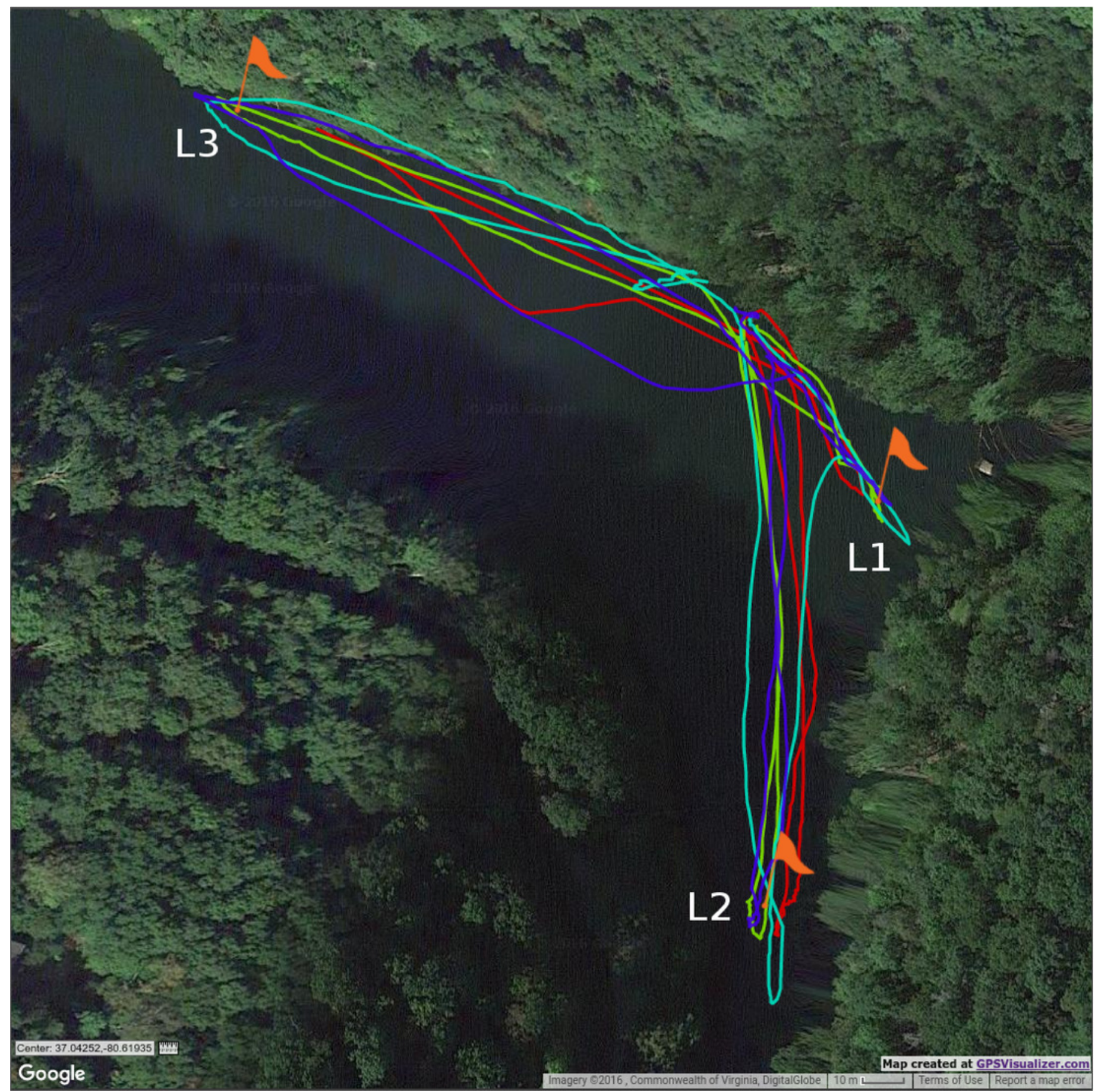




\section{Figure 2}

Image of USV on lake.

The Clearpath Robotics Kingfisher USV equipped with the automated water sampler on Claytor Lake, VA, USA. The water sampler onboard the USV collected samples of water at two different depths. Each sample was collected into sterile $1 \mathrm{~L}$ bottles. The operation of the vacuum pumps and sampling tubes were remote-controlled through a microcontroller and supporting electronics housed in a waterproof box. A collection bottle containing $500 \mathrm{~mL}$ of sterile water was used as an unexposed control during each mission. Image courtesy of D. Schmale.

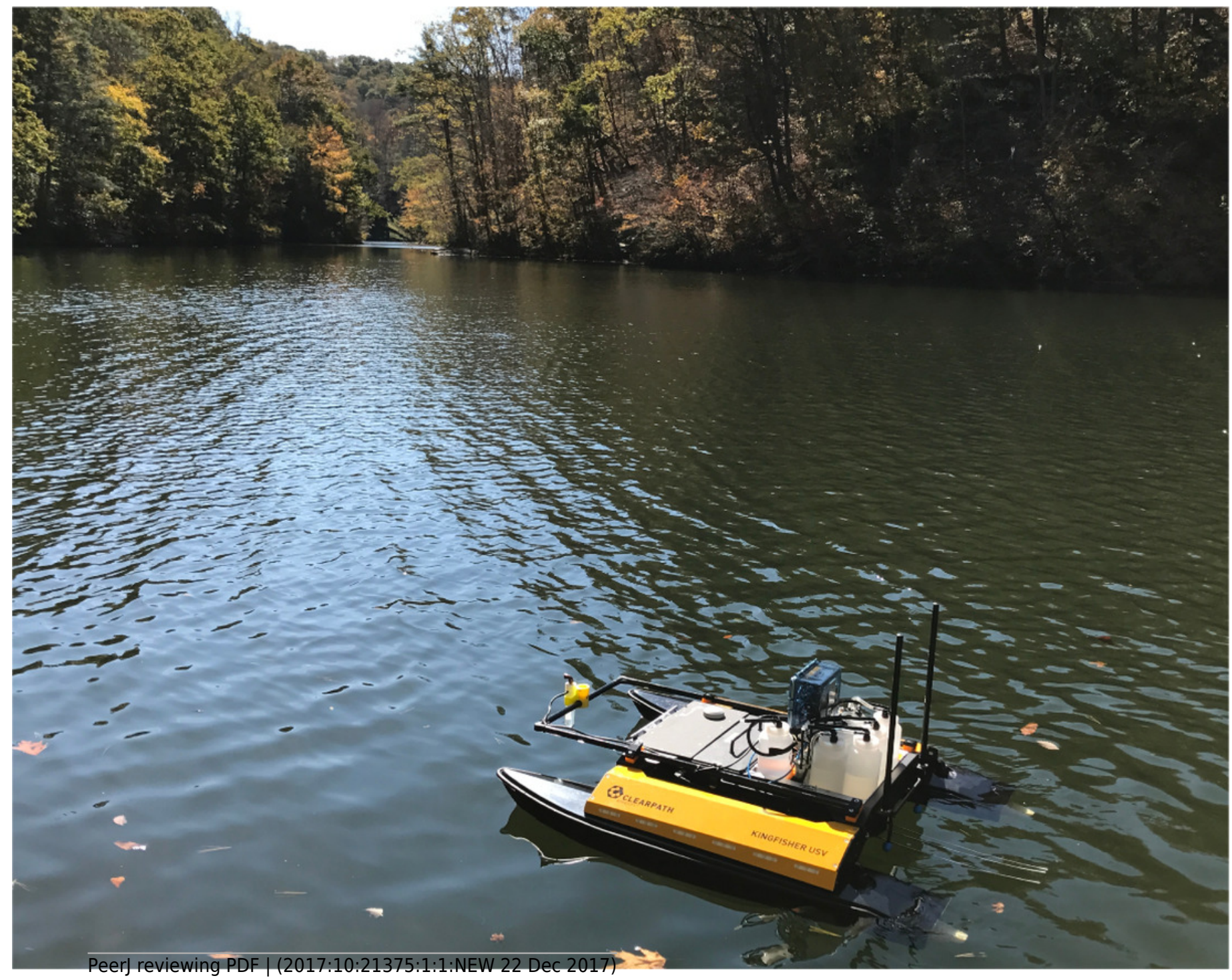




\section{Figure 3}

Engineering design of the automated water sampler onboard the USV.

Engineering design of the automated water sampler onboard the USV. The sampler (A) consisted of a microcontroller and electronics (1) powered by a lithium iron phosphate battery (2) that actuated servos (3) to control siphon positions (4) and pump water into $1 \mathrm{~L}$ containers (5) with vacuum pumps (6). During vehicle movement, the siphon arms (B) were in the stowed configuration (7). Upon reaching the sampling location, the appropriate arm rotated 175 degrees (8) to allow the sterile water in the tube to flow out. The arm then rotated back 90 degrees (9) into the water for collection. After a set amount of collection time, the arm returned to the stowed configuration (7) before proceeding to the next location

A

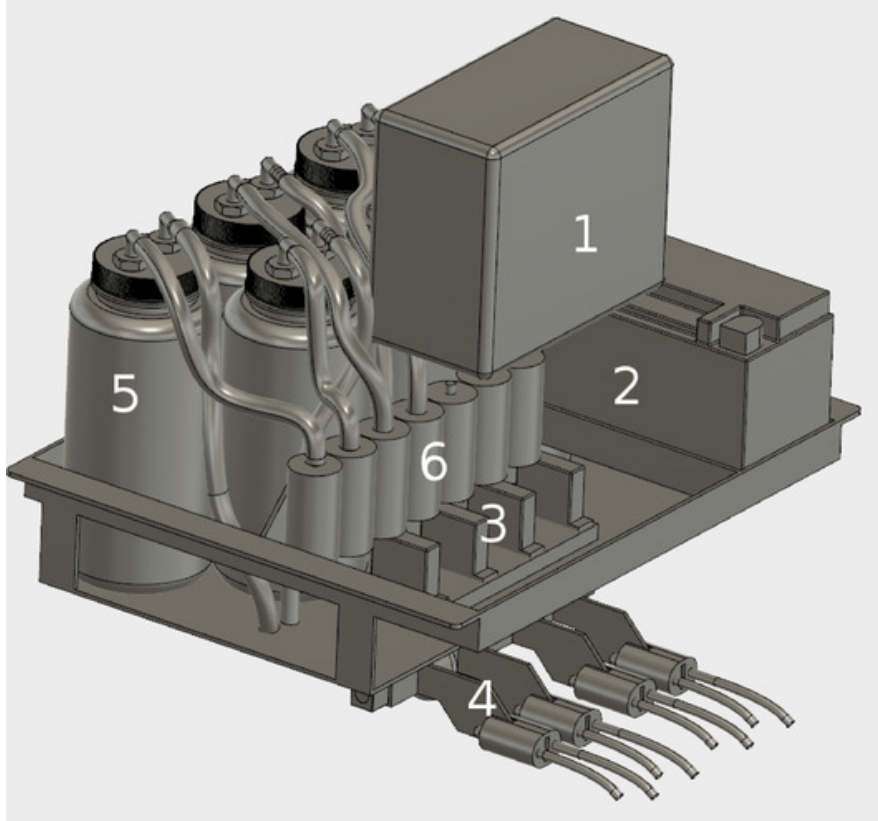

B

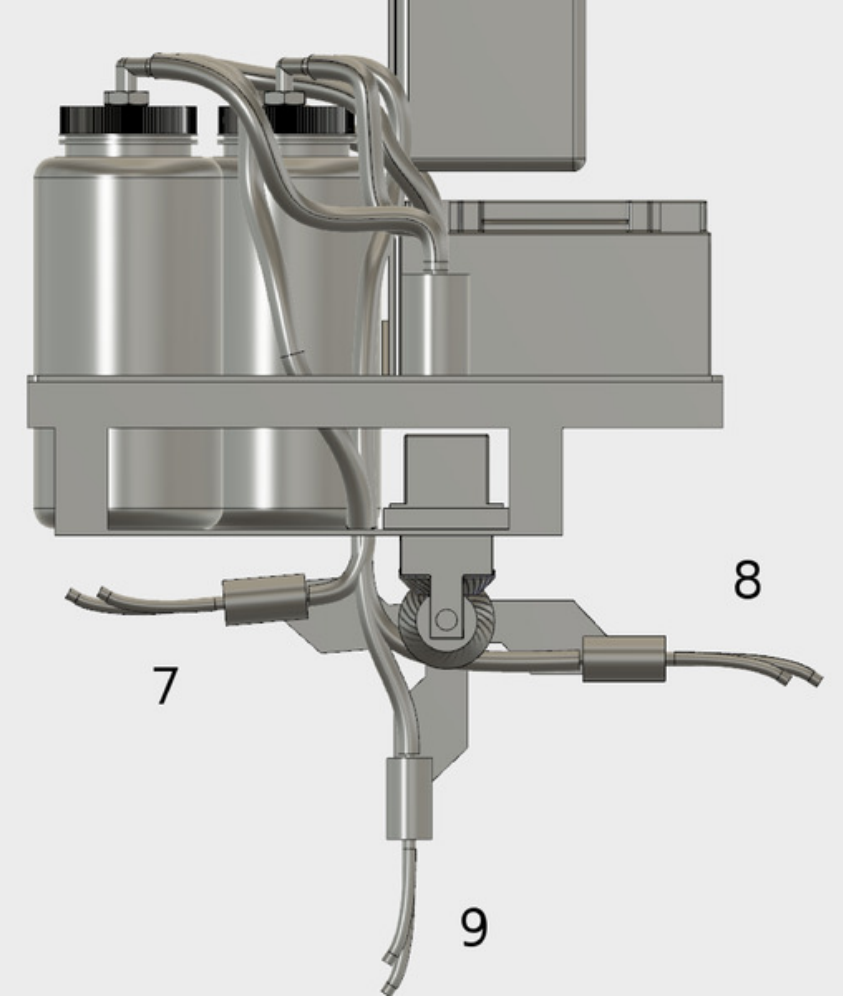


Figure 4

CFU of bacteria on different media.

Concentrations of bacteria (CFU/mL) for TSA (A) and KBC (B) media at two depths of 5 and 50 $\mathrm{cm}$ at the three locations $\mathrm{L} 1, \mathrm{~L} 2$, and $\mathrm{L} 3$.
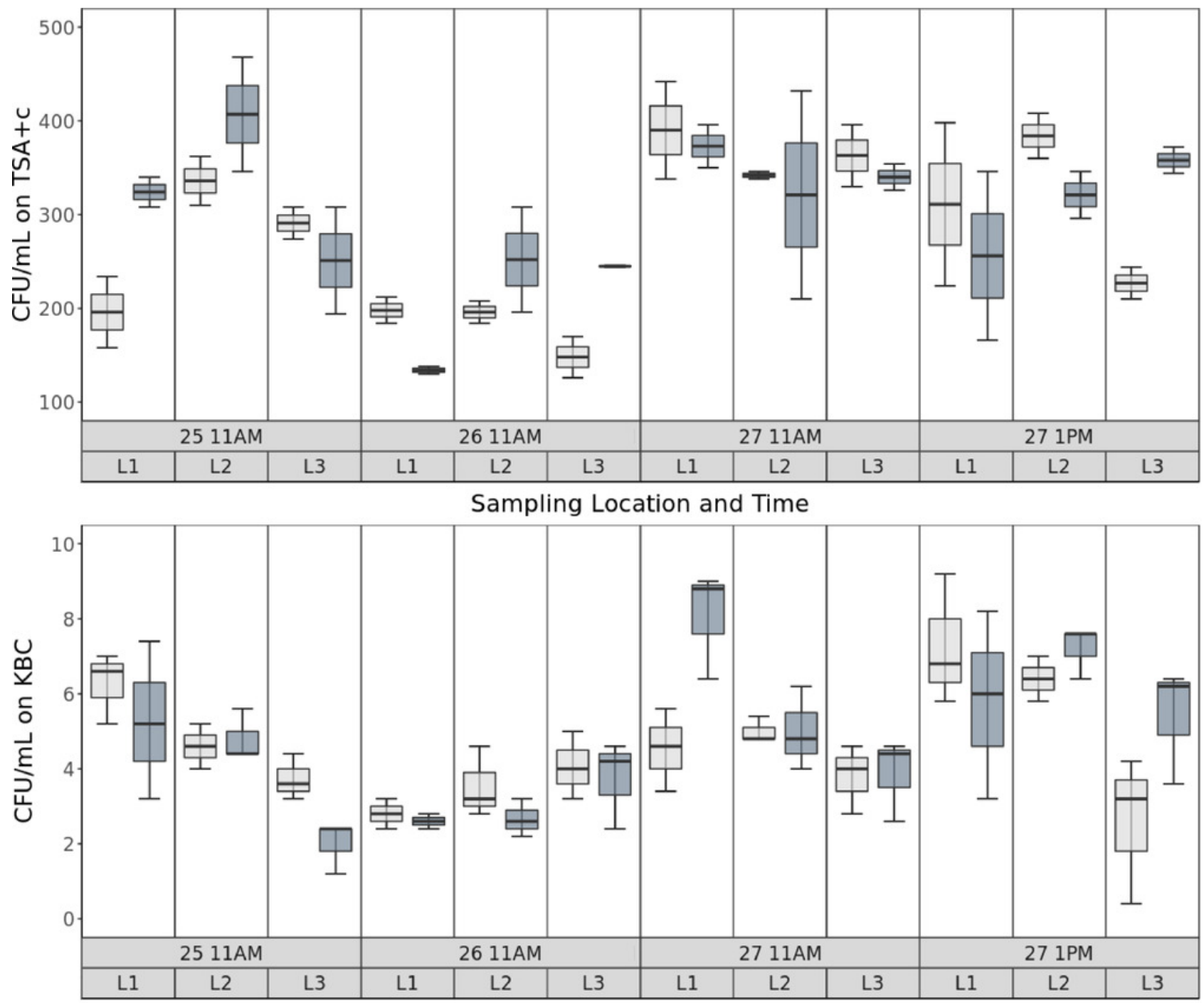

Depth

帛 $5 \mathrm{~cm}$ 官 $50 \mathrm{~cm}$

B

Sampling Location and Time 


\section{Table $\mathbf{1}$ (on next page)}

Microbes cultured from USV samples for different media types.

Mean concentrations of bacteria (CFU/mL) for KBC and TSA media. Data are reported for four sampling missions, over three days, at three locations at Claytor Lake, VA (L1, L2, and L3). Remote collections were performed with a water sampler onboard an unmanned surface vehicle (USV), and $\sim 500 \mathrm{~mL}$ of water was collected for each depth $(5$ and $50 \mathrm{~cm})$ and location. 
1 Table 1. Mean concentrations of bacteria $(\mathrm{CFU} / \mathrm{mL})$ for $\mathrm{KBC}$ and TSA media. Data are reported

2 for four sampling missions, over three days, at three locations at Claytor Lake, VA (L1, L2,

3 and L3). Remote collections were performed with a water sampler onboard an unmanned

4 surface vehicle (USV), and $\sim 500 \mathrm{~mL}$ of water was collected for each depth (5 and $50 \mathrm{~cm}$ )

5 and location.

6

\begin{tabular}{|c|c|c|c|c|c|c|}
\hline Mission & Date & Time & Location & Depth & $\begin{array}{c}\text { Mean CFU/mL } \\
\text { KBC media } \pm \text { SD }\end{array}$ & $\begin{array}{r}\text { Mean CFU } / \mathrm{mL} \\
\mathrm{TSA} \text { media } \pm \mathrm{SD}\end{array}$ \\
\hline 1 & $25-O c t-16$ & 11:00 & L1 $(37.0426,-80.6185)$ & $5 \mathrm{~cm}$ & $6.3 \pm 0.95$ & $196 \pm 53.7$ \\
\hline 1 & 25-Oct-16 & 11:00 & L1 $(37.0426,-80.6185)$ & $50 \mathrm{~cm}$ & $5.3 \pm 2.10$ & $324 \pm 22.6$ \\
\hline 2 & 25-Oct-16 & 11:05 & L2 $(37.0418,-80.6188)$ & $5 \mathrm{~cm}$ & $4.6 \pm 0.60$ & $336 \pm 36.8$ \\
\hline 2 & 25-Oct-16 & 11:05 & L2 $(37.0418,-80.6188)$ & $50 \mathrm{~cm}$ & $4.8 \pm 0.69$ & $407 \pm 86.3$ \\
\hline 3 & 25-Oct-16 & 11:10 & L3 $(37.0433,-80.6201)$ & $5 \mathrm{~cm}$ & $3.7 \pm 0.61$ & $291 \pm 24.0$ \\
\hline 3 & 25-Oct-16 & 11:10 & L3 $(37.0433,-80.6201)$ & $50 \mathrm{~cm}$ & $2.0 \pm 0.69$ & $251 \pm 80.6$ \\
\hline 4 & 26-Oct-16 & 11:00 & L1 $(37.0426,-80.6185)$ & $5 \mathrm{~cm}$ & $2.8 \pm 0.40$ & $198 \pm 19.8$ \\
\hline 4 & 26-Oct-16 & 11:00 & L1 $(37.0426,-80.6185)$ & $50 \mathrm{~cm}$ & $2.6 \pm 0.20$ & $134 \pm 5.66$ \\
\hline 5 & 26-Oct-16 & 11:05 & L2 $(37.0418,-80.6188)$ & $5 \mathrm{~cm}$ & $3.5 \pm 0.95$ & $196 \pm 17.0$ \\
\hline 5 & 26-Oct-16 & 11:05 & L2 $(37.0418,-80.6188)$ & $50 \mathrm{~cm}$ & $2.7 \pm 0.50$ & $252 \pm 79.2$ \\
\hline 6 & 26-Oct-16 & 11:10 & L3 $(37.0433,-80.6201)$ & $5 \mathrm{~cm}$ & $4.1 \pm 0.90$ & $148 \pm 31.1$ \\
\hline 6 & 26-Oct-16 & $11: 10$ & L3 $(37.0433,-80.6201)$ & $50 \mathrm{~cm}$ & $3.7 \pm 1.17$ & $245 \pm 1.41$ \\
\hline 7 & 27-Oct-16 & 11:00 & L1 $(37.0426,-80.6185)$ & $5 \mathrm{~cm}$ & $4.5 \pm 1.10$ & $390 \pm 73.5$ \\
\hline 7 & 27-Oct-16 & 11:00 & L1 $(37.0426,-80.6185)$ & $50 \mathrm{~cm}$ & $8.1 \pm 1.45$ & $373 \pm 32.5$ \\
\hline 8 & 27-Oct-16 & 11:05 & L2 $(37.0418,-80.6188)$ & $5 \mathrm{~cm}$ & $5.0 \pm 0.35$ & $342 \pm 5.66$ \\
\hline 8 & $27-O c t-16$ & $11: 05$ & L2 $(37.0418,-80.6188)$ & $50 \mathrm{~cm}$ & $5.0 \pm 1.11$ & $321 \pm 157$ \\
\hline 9 & 27-Oct-16 & $11: 10$ & L3 $(37.0433,-80.6201)$ & $5 \mathrm{~cm}$ & $3.8 \pm 0.92$ & $363 \pm 46.7$ \\
\hline 9 & 27-Oct-16 & $11: 10$ & L3 $(37.0433,-80.6201)$ & $50 \mathrm{~cm}$ & $3.9 \pm 1.10$ & $340 \pm 19.8$ \\
\hline 10 & 27-Oct-16 & 13:00 & L1 $(37.0426,-80.6185)$ & $5 \mathrm{~cm}$ & $7.3 \pm 1.75$ & $311 \pm 123$ \\
\hline 10 & 27-Oct-16 & 13:00 & L1 $(37.0426,-80.6185)$ & $50 \mathrm{~cm}$ & $5.8 \pm 2.51$ & $256 \pm 127$ \\
\hline 11 & 27-Oct-16 & 13:05 & L2 $(37.0418,-80.6188)$ & $5 \mathrm{~cm}$ & $6.4 \pm 0.60$ & $384 \pm 33.9$ \\
\hline 11 & 27-Oct-16 & 13:05 & L2 $(37.0418,-80.6188)$ & $50 \mathrm{~cm}$ & $7.2 \pm 0.69$ & $321 \pm 35.4$ \\
\hline 12 & 27-Oct-16 & $13: 10$ & L3 $(37.0433,-80.6201)$ & $5 \mathrm{~cm}$ & $2.6 \pm 1.97$ & $227 \pm 24.0$ \\
\hline 12 & 27-Oct-16 & $13: 10$ & L3 $(37.0433,-80.6201)$ & $50 \mathrm{~cm}$ & $5.4 \pm 1.56$ & $358 \pm 19.8$ \\
\hline
\end{tabular}

